\title{
Specific In Planta Recognition of Two GKLR Proteins of the Downy Mildew Bremia lactucae Revealed in a Large Effector Screen in Lettuce
}

\author{
Joost H. M. Stassen, ${ }^{1}$ Erik den Boer, ${ }^{2}$ Pim W. J. Vergeer, ${ }^{1}$ Annemiek Andel, ${ }^{1}$ Ursula Ellendorff, ${ }^{3}$ \\ Koen Pelgrom, ${ }^{2}$ Mathieu Pel, ${ }^{4}$ Johan Schut, ${ }^{3}$ Olaf Zonneveld, ${ }^{5}$ Marieke J. W. Jeuken, ${ }^{2}$ and \\ Guido Van den Ackerveken' \\ ${ }^{1}$ Plant-Microbe Interactions, Department of Biology, Utrecht University, Utrecht, $3584 \mathrm{CH}$, The Netherlands; ${ }^{2}$ Laboratory \\ of Plant Breeding, Wageningen University, Wageningen, 6700 AJ, The Netherlands; ${ }^{3}$ Rijk Zwaan, De Lier, 2678 ZG, The \\ Netherlands; ${ }^{4}$ Enza zaden, Enkhuizen, 1600 AA, The Netherlands; ${ }^{5}$ Syngenta, Enkhuizen, 1601 BK, The Netherlands
}

Submitted 17 May 2013. Accepted 12 July 2013.

Breeding lettuce (Lactuca sativa) for resistance to the downy mildew pathogen Bremia lactucae is mainly achieved by introgression of dominant downy mildew resistance $(\mathrm{Dm})$ genes. New Bremia races quickly render $D m$ genes ineffective, possibly by mutation of recognized host-translocated effectors or by suppression of effector-triggered immunity. We have previously identified 34 potential RXLR(-like) effector proteins of $B$. lactucae that were here tested for specific recognition within a collection of $129 \mathrm{~B}$. lactucaeresistant Lactuca lines. Two effectors triggered a hypersensitive response: BLG01 in 52 lines, predominantly $L$. saligna, and BLG03 in two $L$. sativa lines containing $D m 2$ resistance. The N-terminal sequences of BLG01 and BLG03, containing the signal peptide and GKLR variant of the RXLR translocation motif, are not required for in planta recognition but function in effector delivery. The locus responsible for BLG01 recognition maps to the bottom of lettuce chromosome 9, whereas recognition of BLG03 maps in the RGC2 cluster on chromosome 2. Lactuca lines that recognize the $B L G$ effectors are not resistant to Bremia isolate BI:24 that expresses both BLG genes, suggesting that $\mathrm{Bl}: 24$ can suppress the triggered immune responses. In contrast, lettuce segregants displaying $\mathrm{Dm} 2$ mediated resistance to $B$ remia isolate $B 1: 5$ are responsive to BLG03, suggesting that BLG03 is a candidate Avr2 protein.

The lettuce downy mildew pathogen, Bremia lactucae, causes large losses in susceptible host plants and has been classified as a pathogen with a high risk of quick adaptation to lettuce resistance traits and chemical control (Brown et al.

Current address for J. H. M. Stassen: Laboratory of Phytopathology, Wageningen University, Wageningen, The Netherlands.

Current address for E. den Boer: Rijk Zwaan, De Lier, 2678 ZG, The Netherlands.

Corresponding author: G. Van den Ackerveken;

E-mail: g.vandenackerveken@uu.nl

* The $e$-Xtra logo stands for "electronic extra" and indicates that four supplementary figures, four supplementary tables, and additional supplementary information is published online. Also, Figure 7 appears in color online.

(C) 2013 The American Phytopathological Society
2004; McDonald and Linde 2002). Its large effective population size, high gene flow, and mixed (both sexual and asexual) reproductive system contribute greatly to this risk. B. lactucae belongs to the order Peronosporales, an order of the oomycetes that includes downy mildew and Phytophthora spp. The downy mildews are obligate biotrophs that are found on many plant species, including Arabidopsis (Hyaloperonospora arabidopsidis), cucurbits (Pseudoperonospora cubensis), grapevine (Plasmopara viticola), and sunflower (Plasmopara halstedii). Obligate biotrophs depend on the living host for their growth and reproduction (Kemen and Jones 2012; Spanu 2012). Therefore, for successful infection, it is of prime importance that biotrophs cope with inducible defenses of the host, which can be described as consisting of two overlapping layers of plant immunity (Boller and He 2009; Jones and Dangl 2006; Thomma et al. 2011). The first is triggered by the recognition of pathogen-derived molecules termed pathogen-associated molecular patterns (PAMPs) by transmembrane pattern recognition receptors, and is referred to as PAMP-triggered immunity (PTI). Though pathogens can avoid inducing PTI (e.g., by masking PAMPs), a more common mechanism is the suppression of PTI within the host cell (Jones and Dangl 2006; O'Connell and Panstruga 2006). Pathogens can achieve this by translocating proteins (effectors) into host intracellular compartments where they can manipulate cellular processes (e.g., the suppression of plant defense responses), leading to effector-triggered susceptibility. Gram-negative bacterial pathogens deploy a type III secretion system to bring effectors into the host cytoplasm by means of a pilus-like structure (Büttner and He 2009). Oomycetes get in close contact with host cells by penetrating the plant cell wall and invaginating the plant cell membrane to form haustoria, feeding structures that are thought to contribute to pathogenicity (Avrova et al. 2008; Kemen and Jones 2012; Whisson et al. 2007). From the haustoria, effectors are secreted from the pathogen before they cross the host membrane (Whisson et al. 2007). In the case of the order Peronosporales, two main classes of effectors that enter host cells have been defined: Crinklers and RXLR proteins (Stassen and Van den Ackerveken 2011). The canonical RXLR effector contains an $\mathrm{N}$-terminal signal peptide and a translocation domain that contains an RXLR amino acid motif and, optionally, a dEER motif. The C-terminal part of the protein, following the translocation domain, is referred to as the effector domain. Variations in the presence and exact sequence of motifs in the translocation domain have been observed, e.g., QXLR motifs in P. cubensis 
effectors (Tian et al. 2011) or the presence of an EER motif but not of an RXLR motif in H. arabidopsis ATR5 (Bailey et al. 2011).

A second layer of plant defense is triggered when host cells recognize pathogen effectors. This effector-triggered immunity (ETI) is mediated by resistance $(\mathrm{R})$ proteins, which recognize effectors or their activity on host targets. Most known $\mathrm{R}$ proteins belong to the family of cytoplasmic nucleotide binding (NB) and leucine-rich repeat (LRR) proteins (Dangl and Jones 2001; Jones and Dangl 2006; Takken and Goverse 2012). Defense triggered by recognition of effectors by $R$ proteins is often associated with the hypersensitive response (HR) that is visible as programmed cell death of host tissue. Effectors that are recognized by host $\mathrm{R}$ proteins and trigger $\mathrm{HR}$ are termed avirulence proteins (AVRs). All AVRs cloned from oomycete pathogens thus far are RXLR and RXLR-like effectors ( $\mathrm{Na}$ et al. 2013; Song et al. 2013; Stassen and Van den Ackerveken 2011; Wang et al. 2011), with the exception of ATR5 (Bailey et al. 2011). RXLR effectors are predicted to be present in large numbers in the genomes of oomycetes belonging to the order Peronosporales, from 134 in $\mathrm{H}$. arabidopsidis (Baxter et al. 2010) to 563 in Phytophthora infestans (Haas et al. 2009). RXLR effectors are highly diverse between species (Jiang et al. 2008) and can also be differentially present within different isolates of a pathogen species (Cabral et al. 2011; Wang et al. 2011). Oomycete pathogens rapidly evolve to overcome R-protein-mediated recognition or ETI by i) amino acid substitutions in the effector protein (Armstrong et al. 2005; Gilroy et al. 2011); ii) downregulation, loss, or silencing of the effector gene (Na et al. 2013 Qutob et al. 2009) or premature stop codons in the sequence (Song et al. 2013); or iii) suppression of ETI by other effectors (Fabro et al. 2011; Guo et al. 2009; Wang et al. 2011). Therefore, resistance is the outcome of a complex network of interactions between effectors and components of the host's defense machinery. Unraveling such a network requires knowledge about the individual interactions between effectors, $\mathrm{R}$ proteins, and host targets.

The interaction between lettuce and B. lactucae has been extensively studied as a host-pathogen model for gene-forgene interactions (Michelmore and Wong 2008). More than 40 major downy mildew-resistance $(D m)$ genes are known, as well as minor-effect $R$ genes that may confer partial or field resistance. A single $D m$ gene, $D m 3$, has been cloned and is part of a large locus of several megabases known as $R$ gene candidate 2 (RGC2) locus (Meyers et al. 1998) that contains at least 30 other NB-LRR genes (Kuang et al. 2004).

Cultivated lettuce (Lactuca sativa) can be crossed, with some difficulty, with wild lettuce species that include Lactuca spp. that are considered B. lactucae nonhosts (e.g., L. saligna). These wild lettuce species provide a pool of genetic material from which new $D m$ genes and resistance quantitative trait loci (QTLs) have been identified (Jeuken and Lindhout 2002; Van Treuren et al. 2011; Zhang et al. 2009a). Dominant $R$ genes have been extensively used to breed $B$. lactucae-resistant lettuce cultivars. However, turnover of $D m$ genes has been rapid, because $B$. lactucae is quick to adapt to newly introduced $R$ genes. To understand the molecular basis of ETI in the lettuce$B$. lactucae interaction and to identify new $R$ genes for resistance breeding, we deployed a selection of 34 B. lactucae candidate RXLR and RXLR-like effectors, which were previously identified by transcriptome sequencing (Stassen et al. 2012), to screen a large collection of lettuce breeding lines for new recognition specificities. We discovered two proteins, containing the newly found RXLR-like variant GKLR that are recognized in planta, one of which is recognized by L. sativa cultivars containing the $D m 2$ gene.

\section{RESULTS}

\section{Screening Lactuca accessions}

for recognition of 34 Bremia effectors.

Previously, we predicted 77 potential RXLR and RXLR-like effectors from our B. lactucae transcriptome data (Stassen et al. 2012). From these, we cloned a set of 16 full-length effector candidates and, from previous $B$. lactucae transcript assemblies, we cloned and verified 12 potential effectors. Finally, we obtained the full coding sequence of six potential effectors that were not full-length in the assembled 454-transcript data by using short reads of spore-derived genomic DNA or by $3^{\prime}$ rapid amplification of cDNA ends. The coding sequences of all 34 B. lactucae effector candidates were cloned in a GATEWAY ENTRY plasmid and confirmed by Sanger sequencing (the nucleotide and protein sequences can be found in Supplementary Information S1).

A summary of features of the candidate effector proteins is given in Table 1 for 30 B. lactucae RXLR (BLR) proteins that contain the canonical RXLR motif and 4 candidates with an alternative RXLR-like motif that were predicted based on their similarity to effectors of other oomycetes and by comparison with a hidden Markov model based on the amino acid sequence surrounding the RXLR motifs of the BLRs. In three of these RXLR-like motifs, the first residue is not an arginine but a glycine (named BLG01, BLG02, and BLG03) and, in the fourth RXLR-like protein, this residue is a glutamine (named BLQ01). EER-like domains (rich in $\mathrm{E}, \mathrm{Q}, \mathrm{D}$, or $\mathrm{N}$ residues, preferably ending in $\mathrm{R}$ or $\mathrm{K}$ ) were found in the 25 of the 34 effector candidates, including in the BLG proteins that have a conserved DER sequence. The length of the predicted effector proteins varied from 65 to 463 amino acids, with an average of just under 180 amino acids.

Recognition of effectors in planta can be efficiently tested by transient expression of the corresponding B. lactucae coding sequences using Agrobacterium tumefaciens for delivery to plant cells. Because all known RXLR(-like) effectors that are recognized by plant $R$ proteins are host-translocated, we engineered the coding sequences such that the signal peptide sequences were removed $(\Delta \mathrm{SP})$ and replaced by new start codons in front of the predicted signal peptide cleavage sites. Infiltration of lettuce leaves with Agrobacterium spp. carrying a T-DNA vector with the $\Delta \mathrm{SP}$ coding sequences under control of the 35S Cauliflower mosaic virus promoter results in production of the $\Delta \mathrm{SP}$-effector protein in the plant cell cytoplasm, the same location at which the protein is thought to arrive when secreted from $B$. lactucae and translocated into the host cell. Intracellular recognition of effectors by $R$-gene-encoded proteins is expected to induce a clearly visible cell death response, also referred to as the HR. Because no B. lactucae effectors are known, thus far, that trigger HR in Lactuca spp., we made use of the cell-death-inducing protein PsojNIP of the oomycete $P$. sojae that was previously used as a positive control for transient expression in L. sativa (Jeuken et al. 2009). Necrotic lesions developed, starting from 2 days postAgrobacterium spp. infiltration, in response to transient expression of PsojNIP but not in response to expression of either yellow fluorescent protein (YFP) or $\beta$-glucuronidase (GUS). Results were similar in all other Lactuca spp. tested (e.g., in L. saligna and L. acaleata) (Supplementary Fig. S1).

In total, 129 Lactuca accessions or lines were selected, representing a broad range of $B$. lactucae resistances, including dominant $D m$ genes and partial or quantitative resistance traits, as well as additional genetically unknown forms of resistance to B. lactucae (Supplementary Table S1). The collection of 129 Lactuca lines was screened for effector recognition by Agrobacterium infiltration of the 34 different effector constructs. 
Agrobacterium-mediated transient expression was robust in nearly all tested lines, as can been seen from the cell death response that is induced by PsojNIP expression. None of the tested lines showed a strong response to Agrobacterium with the YFP construct. Average scores were given per lettuceeffector combination based on the presence of no or few visible symptoms (0), strong yellowing of the leaf (1), or cell death (2). The responses of the Lactuca lines to each of the 34 effectors, defined as an average score, are summarized in Supplementary Table S2. Two of the 34 effectors, BLG01 and BLG03, induced clear cell death responses (average symptoms scores $\geq 1.3$ ) in several Lactuca lines. Four other effectors were found to induce cell death in a single line in one experiment; however, the specific recognition could not be confirmed for these combinations.

Recognition of the RXLR-like proteins BLG01 and BLG03.

A variant of the mature (without signal peptide) protein, BLG01 ${ }^{\mathrm{E}}$ - based on an allele from B. lactucae isolates NL519 and F703 - was found to induce a stronger response than the protein encoded by our reference strain $\mathrm{Bl}: 24\left(\mathrm{BLG} 01^{\mathrm{A}}\right)$. Of the 129 tested lines, 41 gave a strong cell death response to BLG01 ${ }^{\mathrm{E}}$. Weak or inconsistent responses to $\mathrm{BLG} 01^{\mathrm{A}}$ and BLG01 ${ }^{\mathrm{E}}$ were observed for 16 and 8 Lactuca lines, respectively (reviewed in Supplementary Figure S2). The higher number of BLG01 ${ }^{\mathrm{E}}$-responsive lines is likely due to a stronger response that is more easily detected, because most lines that showed a weak response to $\mathrm{BLG} 01^{\mathrm{A}}$ showed a strong response to $\mathrm{BLG} 01^{\mathrm{E}}$. Additionally, the response of 16 lines is only visible with $\mathrm{BLG} 01^{\mathrm{E}}$ but not with BLG01 ${ }^{\mathrm{A}}$. Most of the Lactuca lines in our collection that showed a response to BLG01 were of the $L$. saligna species. BLG01 recognition in a few responsive $L$. serriola and $L$. virosa lines could not be confirmed in additional transient expression experiments (Supplementary Table S3), suggesting that BLG01 recognition is specific for L. saligna.

A second effector, BLG03, was specifically recognized in two L. sativa lines, Amplus and UCDM2 (Fig. 1). In all other lines, BLG03 did not induce responses that could be distinguished from the GUS negative control (e.g., in 'Olof'). The
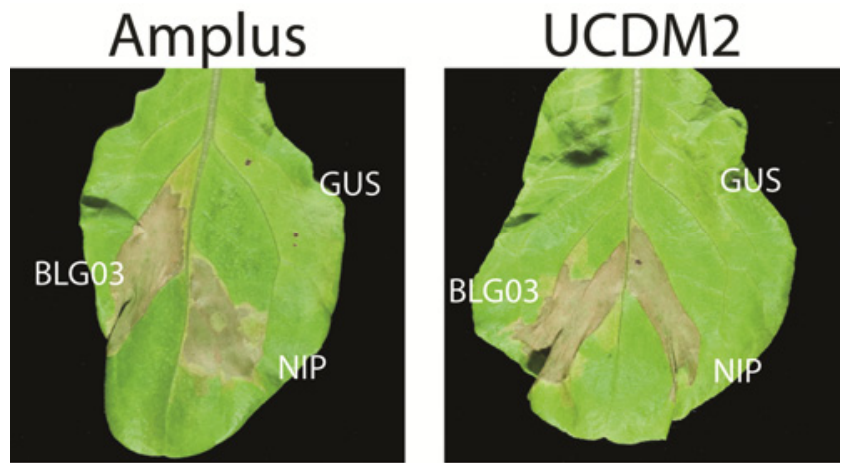

Fig. 1. Hypersensitive response triggered by BLG03 in Lactuca sativa Amplus and UCDM2. $\beta$-Glucuronidase (GUS) and PsojNIP (NIP) serve as controls for responses to Agrobacterium and successful T-DNA transfer, respectively. Pictures were taken 6 days postinoculation.

Table 1. Overview of cloned Bremia lactucae effector candidates ${ }^{\mathrm{z}}$

\begin{tabular}{|c|c|c|c|c|c|c|c|}
\hline \multirow[b]{2}{*}{ ID } & \multirow[b]{2}{*}{ Source } & \multirow[b]{2}{*}{ Contig ID } & \multirow[b]{2}{*}{ Length } & \multicolumn{2}{|c|}{ RXLR-like } & \multicolumn{2}{|c|}{ EER-like } \\
\hline & & & & Start & Motif & Start & Motif \\
\hline BLR01 & $\mathrm{P}$ & - & 86 & 42 & RKLR & 52 & EQK \\
\hline BLR02 & $\mathrm{P}$ & - & 146 & 85 & RLLR & $\ldots$ & $\ldots$ \\
\hline BLR03 & $\mathrm{P}$ & - & 141 & 48 & RFLR & 59 & EEER \\
\hline BLR04 & $\mathrm{P}$ & - & 76 & 45 & RELR & 60 & DIK \\
\hline BLR05 & $\mathrm{P}$ & - & 97 & 32 & RALR & 58 & DED \\
\hline BLR06 & $\mathrm{P}$ & - & 281 & 46 & RCLR & $\ldots$ & $\ldots$ \\
\hline BLR07 & $P$ & - & 253 & 47 & RALR & 68 & EEER \\
\hline BLR08 & $\mathrm{P}$ & - & 135 & 38 & RLLR & $\ldots$ & $\ldots$ \\
\hline BLR09 & $\mathrm{P}$ & - & 112 & 37 & RRLR & 81 & EER \\
\hline BLR10 & $\mathrm{P}$ & - & 112 & 37 & RRLR & 81 & EER \\
\hline BLR11 & $\mathrm{P}$ & - & 463 & 46 & RRLR & 57 & DESER \\
\hline BLR12 & $\mathrm{P}$ & - & 123 & 49 & RYLR & 61 & ELEK \\
\hline BLR13 & M & 16131 & 363 & 44 & RRLR & 55 & EER \\
\hline BLR14 & M & 29191 & 75 & 46 & RKLR & & \\
\hline BLR15 & M & 50216 & 102 & 47 & RSLR & 60 & DEER \\
\hline BLR16 & M & $32917-1$ & 98 & 47 & RSLR & 60 & NDER \\
\hline BLR17 & M & 18684 & 282 & 50 & RRLR & 64 & DAEK \\
\hline BLR18 & M & 48006 & 92 & 46 & RALR & 55 & NEDR \\
\hline BLR19 & M & 31910 & 160 & 45 & RLLR & 54 & DNNEER \\
\hline BLR20 & M & 45396 & 130 & 53 & RLLR & 69 & DEAD \\
\hline BLR21 & M & 33962 & 65 & 39 & RILR & $\ldots$ & $\ldots$ \\
\hline BLR22 & M & 43968 & 185 & 33 & RGLR & $\ldots$ & $\ldots$ \\
\hline BLR23 & M & 24965 & 107 & 57 & RSLR & 62 & DENR \\
\hline BLR24 & M & 43687 & 91 & 55 & RSLR & 74 & ELEQ \\
\hline BLR25 & M & 48013 & 82 & 55 & RALR & $\ldots$ & $\ldots$ \\
\hline BLR26 & $\mathrm{E}$ & 16394 & 187 & 46 & RRLR & 59 & QNDER \\
\hline BLR27 & E & 38529 & 434 & 40 & RQLR & $\ldots$ & $\ldots$ \\
\hline BLR28 & 3 & 08983 & 279 & 49 & RRLR & $\ldots$ & $\ldots$ \\
\hline BLR29 & 3 & 43449 & 311 & 35 & RMLR & 46 & EES \\
\hline BLR30 & 3 & 50216 & 101 & 47 & RSLR & 60 & DEER \\
\hline BLQ01 & 3 & 59265 & 79 & 49 & QLLR & 61 & DEEQR \\
\hline BLG01 & M & 25695 & 336 & 44 & GKLR & 57 & DER \\
\hline BLG02 & M & 31920 & 233 & 44 & GRLR & 57 & DER \\
\hline BLG03 & M & 23857 & 243 & 42 & GKLR & 55 & DER \\
\hline
\end{tabular}

${ }^{\mathrm{z}}$ The first RXLR or RXLR-like motif and position within 100 amino acids from the start codon are indicated. The first EER or EER-like motif and position of which the first amino acid is within 20 amino acids of the first amino acid of the RXLR motif are shown. Source: $M=$ main assembly, $3=3^{\prime}$ rapid amplification of cDNA ends, $\mathrm{E}=$ transcript extended with $\mathrm{SOLiD}$ data, and $\mathrm{P}=$ preliminary assemblies. 
set of cultivated lettuce lines (L. sativa) included in the screen contains differential lines that provide a wide range of genetically known $R$ genes and can be used to determine $R$-gene specificities. Both Amplus and UCDM 2 contain the Dm 2 resistance specificity that is absent in all other $L$. sativa lines tested. Therefore, Dm 2 could mediate the recognition of BLG03.

Strikingly, BLG01 and BLG03 both contain the RXLR-like motif GKLR. In addition, the signal peptide- and GKLR-containing N-termini of BLG01 and BLG03 are 63\% similar (Fig. 2). The N-terminus of a third B. lactucae protein, BLG02, also shows homology to these effectors. However, BLG02 is not recognized in any of the lettuce lines tested. The GKLR and DER motifs are identical in BLG01 and BLG03, whereas BLG02 has a GRLR variant of the RXLR motif. The effector domains (C-terminal of the DER motifs) do not share the high level of similarity that is seen for the signal peptides and $\mathrm{G}^{\mathrm{K}} / \mathrm{R}_{\mathrm{R}} \mathrm{LR}$-containing $\mathrm{N}$-termini but are only $45 \%$ similar.

BLG01, BLG02, and BLG03 do not have significant homology to any sequences in the National Center for Biotechnology Information nonredundant protein database (e value $<1 \mathrm{e}-3$ ), nor are there any significant matches to Pfam domains (Finn et al. 2010). The best BLAST matches in a combined database of oomycete proteins (H. arabidopsidis, $P$. infestans, $P$. ramorum, P. sojae, Pythium ultimum, and Saprolegnia parasitica) were to a putative Phytophthora infestans RXLR effector (PITG_ 15128 , e value $=0.037$ ) for BLG01, a $P$. sojae RXLR effector (Ps_133875, e value $=0.81)$ for BLG03, and a $P$. ramorum RXLR effector $($ Pr_97351, e value $=0.032)$ for BLG02 (Supplementary Information S2).

\section{$B L G 01$ and $B L G 03$ expression.}

In order to be recognized in planta, these $\mathrm{G}^{\mathrm{K}} / \mathrm{R}_{\mathrm{R}} \mathrm{LR}$ effectors need to be expressed during the infection process. Expression in planta was already observed, because the effector transcripts were previously identified by transcriptome sequencing of infected lettuce leaves (Stassen et al. 2012). To determine the changes in expression during the different stages of infection, we analyzed a time series by quantitative polymerase chain reaction (qPCR) (Fig. 3). L. sativa 'Olof' seedlings were spray-inoculated with spores of B. lactucae isolate $\mathrm{Bl}: 24$, after which samples were taken every $24 \mathrm{~h}$, starting immediately after spraying. Within the first $24 \mathrm{~h}$, the majority of spores germinated and $B$. lactucae had penetrated the epidermis. Substantial $B$. lactucae hyphal growth and formation of haustoria in mesophyll cells occurred over the next 4 days. At 6 days postinoculation (dpi), conidiophores formed and sampling was stopped. The expression of B. lactucae actin relative to $L$. sativa actin shows the substantial relative growth of B. lactucae throughout the entire time course (Fig. 3). Expression of BLG03 increases immediately after inoculation and appears to be stable from 1 dpi onward. BLG01 gene expression decreases slightly during the course of infection, with expression levels comparable with those of BLG03 at the later stages of infection. BLG02 shows an increase of expression at the first day after inoculation similar to that of BLG03. After $1 \mathrm{dpi}$, expression levels of BLG02 decline, approaching the level seen immediately after inoculation. Similar expression in time was detected in an independent biological replicate. These results confirm that the three BLG

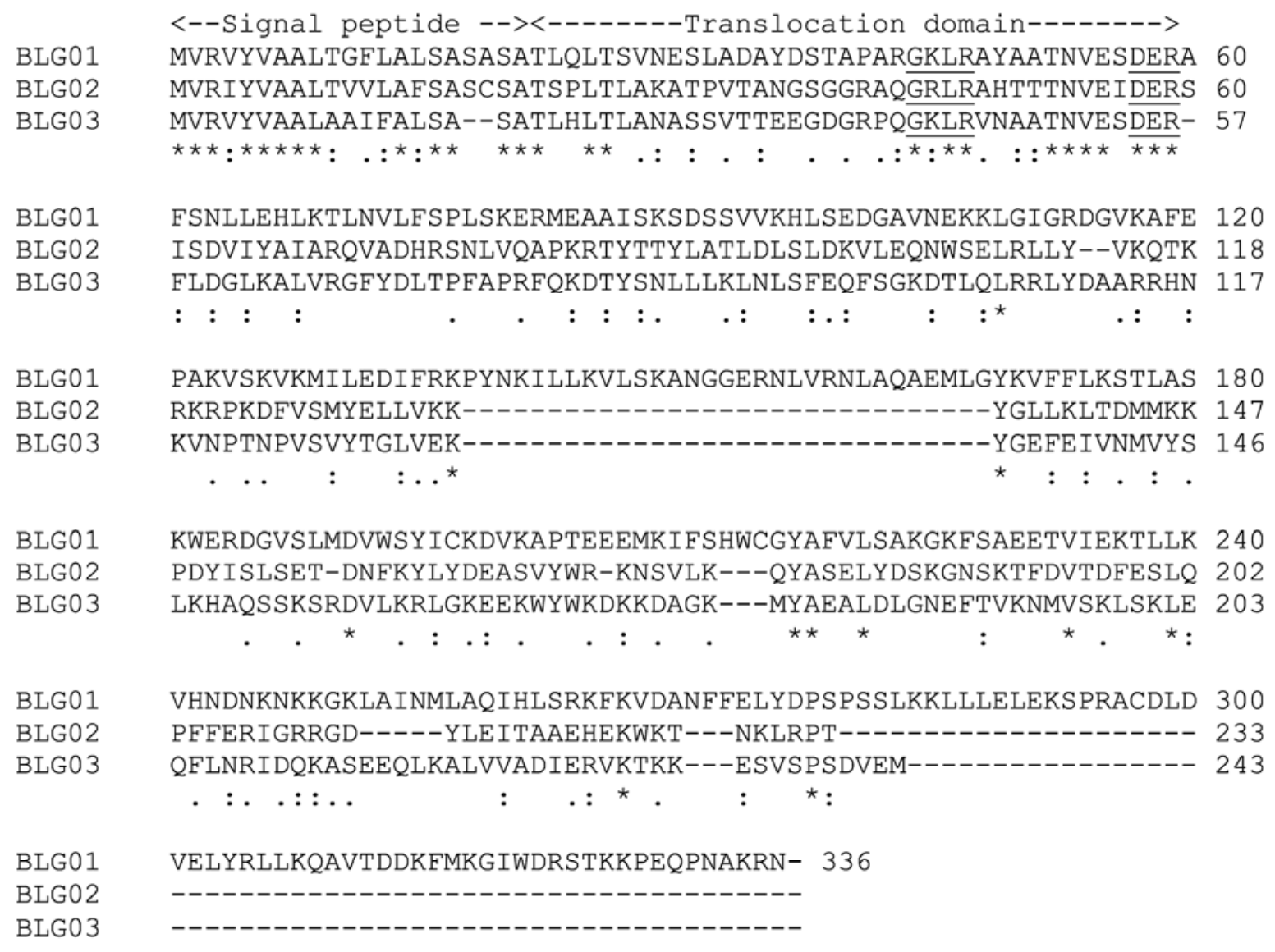

Fig. 2. Alignment of the amino acid sequence of candidate effectors BLG01, BLG02, and BLG03. Signal peptide and translocation domains are indicated above the alignment and the GXLR and DER motifs are underlined in the alignment. Symbols under the alignment indicate the degree of conservation of the above residues and indicate identical (*) residues, the presence of conserved substitutions (:), or semiconserved substitutions (.). Numbers to the right of the alignment indicate the residue number of the last residue in the column counted from the start of the protein, skipping gaps. 
genes are expressed from 0 to $5 \mathrm{dpi}$, suggesting that the effector proteins are produced at all stages of infection.

\section{The GKLR domains of BLG01 and BLG03 are required for translocation but not for effector recognition.}

The recognition of the BLG01 and BLG03 effectors is thought to occur in the host cell cytoplasm. To test whether the GKLR and DER motifs are needed for effector recognition, we investigated whether the effector domains of BLG01 and BLG03 are sufficient for recognition when expressed in lettuce. Using the same Agrobacterium-mediated transient transformation system as used to screen the collection of lettuce lines, we expressed BLG01 ${ }^{60-336}$ in the responsive L. saligna line CGN05271 and BLG03 ${ }^{58-243}$ in the responsive UCDM2 line. Cell death responses in the zones infiltrated with BLG01 ${ }^{60-336}$ did not differ from those infiltrated with BLG01 with translocation domain (BLG0122-336) (Fig. 4), indicating that the translocation domain (BLG01 ${ }^{22-60}$ ) is not required for in planta recognition in CGN05271. Similarly, the recognition of BLG03 is also independent of the translocation domain (BLG03 ${ }^{20-58}$, as shown by the cell death response induced by BLG03 ${ }^{58-243}$ (Fig. 5).

To test whether the GKLR- and DER-containing domains mediate translocation of the effectors, we tested the translocation domain of BLG01 and BLG03 in the AVR3a-translocation assay in P. capsici (Schornack et al. 2010). The assay is based on recognition of transgenic $P$. capsici strains by Nicotiana benthamiana plants expressing R3a. The $P$. capsici strains express a fusion of the signal peptide and translocation domain of interest to the effector domain of AVR3a, which is recognized intracellularly by $\mathrm{R} 3 \mathrm{a}$, only if the translocation domain is able to mediate translocation. $P$. capsici transformed with an empty vector was able to spread from the initial infection site in $100 \%$ of wild-type N. benthamiana plants and $70 \%$ of R3a-expressing plants (Fig. 6). The CRN16:Avr3a fusion (Schornack et al. 2010) was used as positive control and transformants containing this construct caused spreading lesions from $95 \%$ of infection sites on wild-type plants but only in $12.5 \%$ of infection sites on R3aexpressing plants. P. capsici transformants expressing BLG01: AVR3a and BLG03:AVR3a fusions spread from 58 and $46 \%$ of infection sites, respectively, on wild-type plants. By contrast, no spreading lesions were observed on R3a-expressing $N$. benthamiana plants, strongly suggesting that the BLG01 and BLG03 GKLR- and DER-containing domains mediate translocation. Transformants expressing BLG01:AVR3a and BLG03:AVR3a constructs in which the GKLR motif was substituted by AAAA caused more spreading lesions on R3a plants than the nonmutated BLG:AVR3a transformants, suggesting that disruption of the GKLR motif prohibits efficient translocation (Supplementary Fig. S3).

\section{Allelic diversity of GXLR effectors.}

Allelic diversity of the three $\mathrm{G}^{\mathrm{K}} /{ }_{\mathrm{R}} \mathrm{LR}$ effectors in a selection of $B$. lactucae isolates was investigated to test whether the proteins showed signs of selection. A set of eight B. lactucae isolates was chosen as a group with high diversity based on their $R$ gene specificities. Because $B$. lactucae is diploid, a single isolate can contain different alleles. To determine possible alleles, PCR products were cloned and, from each isolate, at least eight clones per gene were sequenced. Seven different alleles were found for BLG01 and BLG03 and six alleles for BLG02. The distribution of alleles is represented in Table 2 and the protein translations of the different alleles can be found in Supplementary Information S3. Two striking observations can be made regarding BLG01. First, as can be seen from the allele distribution, isolate B1:5 appears to possess four alleles of this effector, which could be due to gene duplication or polyploidy. Second, the allele sequences reveal that no functional BLG01 proteins are encoded in isolates NL519 and F703 due to a nonsense mutation in the fifth codon (TAC $\rightarrow$ TAA, $\mathrm{Y} \rightarrow$ stop). The same stop is found in one of the alleles of $\mathrm{Bl}: 5$, whereas two other B1:5 alleles have premature stops at other positions. In one of these alleles, the stop (CAG $\rightarrow$ TAG, $\mathrm{Q} \rightarrow$ stop) is at amino acid position 24 , the third residue after the predicted signal peptide cleavage site (SA|TL); in the other case, a two-nucleotide deletion in the effector domain (amino acid position 286) induces a frame shift that reads into a stop after two amino acids. In contrast to NL519 and F703, a fulllength copy of the effector is present in Bl:5. For most isolates, two different alleles of BLG02 and BLG03 were found. BLG02 ${ }^{\mathrm{A}}$ and $\mathrm{BLG} 02^{\mathrm{B}}$ encode the same protein sequence and only have synonymous nucleotide variants. All amino acid differences encoded in BLG02 alleles were found in the effector domain. This is in contrast to BLG03, in which amino acid polymorphisms are also found in the signal peptide and translocation domain. Although one allele has an insertion of two amino acids in the signal peptide, all BLG03 alleles are predicted to encode a signal peptide. BLG03 ${ }^{\mathrm{F}}$, only present in $\mathrm{Bl}: 17$, has a premature stop codon in the effector domain. Furthermore, $\mathrm{BLG}^{\mathrm{G}}{ }^{\mathrm{G}}$, found in $\mathrm{Bl}: 5$, is more sequence divergent from the Bl:24 reference sequence than all other BLG03 alleles. None of our effectors are predicted to be under positive selection to maintain amino acid diversity based on the ratio of synonymous $(\mathrm{dS})$ to nonsynonymous $(\mathrm{dN})$ substitutions (codon-based test of positive selection averaging over all sequence pairs:

Bremia growth

Gene expression
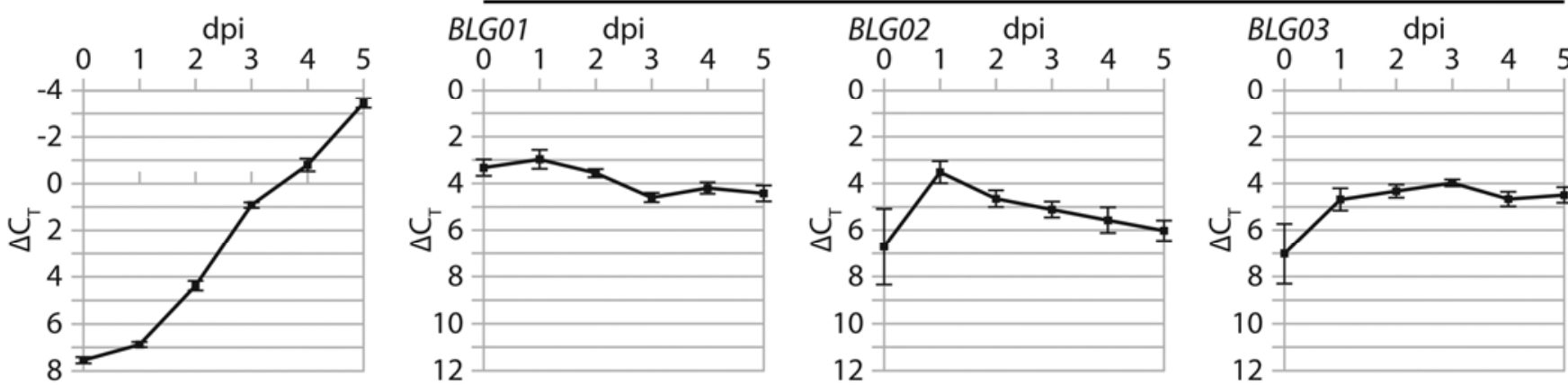

Fig. 3. Bremia lactucae isolate $\mathrm{B1}: 24$ growth and effector gene expression during infection of Lactuca sativa 'Olof'. Growth is inferred by the increase of $B$. lactucae actin relative to lettuce actin throughout the time course calculated as cycle threshold $\left(\Delta \mathrm{C}_{\mathrm{T}}\right)$. Effector gene expression is determined relative to B. lactucae actin. The difference in $\mathrm{C}_{\mathrm{T}}$ required to reach threshold is given; because lower values indicate higher expression, the $y$ axis has been reversed to ease interpretation. 
BLG01, Z score $=0.05790, p=0.47696 ; \mathrm{BLG} 02, \mathrm{Z}$ score $=$ $0.15217, P=0.43965$; and BLG03, $\mathrm{Z}$ score $=-1.31461, P=$ 1.0). However, the many different alleles and, in particular, the nonsense alleles suggest that BLG01 and BLG03 have been under selective pressure.

The different BLG01 alleles were next used to make constructs of the effector without signal peptide for in planta expression. Constructs with the effector domains of all BGL01 alleles except $\mathrm{F}$ were tested in $L$. saligna CGN5271 to determine their potential to trigger cell death. BLG01 ${ }^{\mathrm{D}}$ and $\mathrm{BLG} 01^{\mathrm{G}}$ did not appear to induce cell death in CGN5271. Strikingly, the effector domain of $\mathrm{BLG01}{ }^{\mathrm{E}}$ triggered the strongest responses when expressed in L. saligna CGN05271 and, as a result, provided more clear-cut scoring (Supplementary Fig. S4). However, because there is a premature stop in the signal peptide of
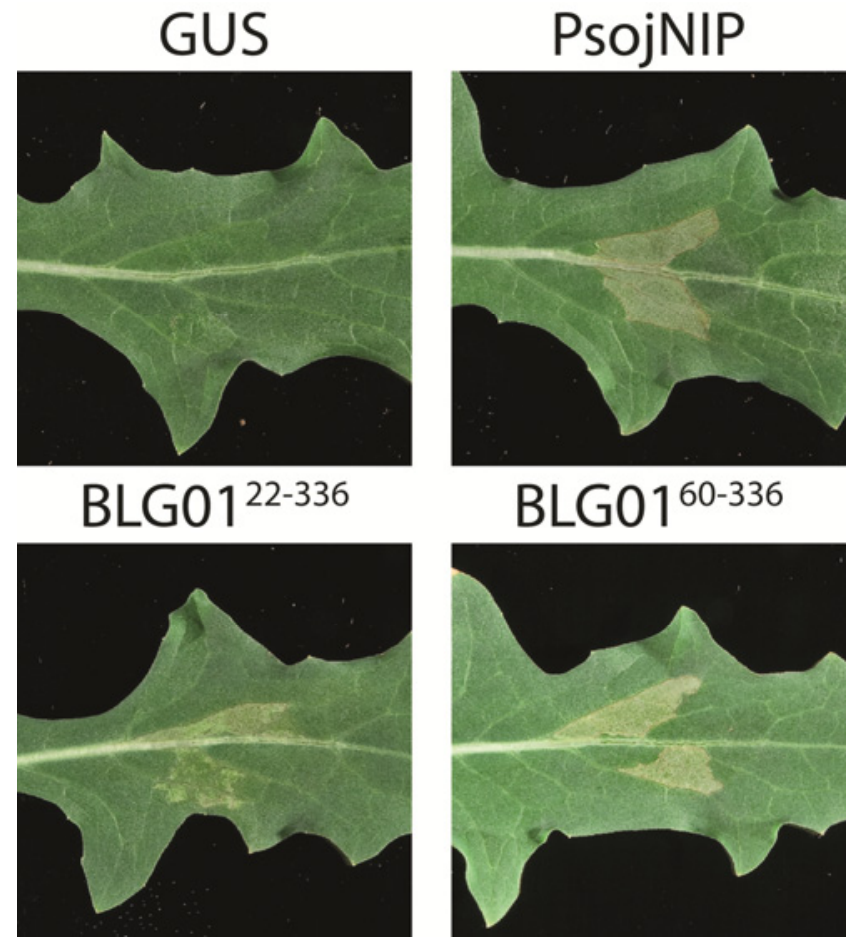

Fig. 4. Recognition of BLG01 without signal peptide (BLG0122-336) and without signal peptide and translocation domain (BLG01 ${ }^{60-336}$ ) in Lactuca saligna CGN05271. $\beta$-Glucuronidase (GUS) and PsojNIP serve as controls for responses to Agrobacterium and successful T-DNA transfer, respectively. Pictures were taken 8 days postinoculation.
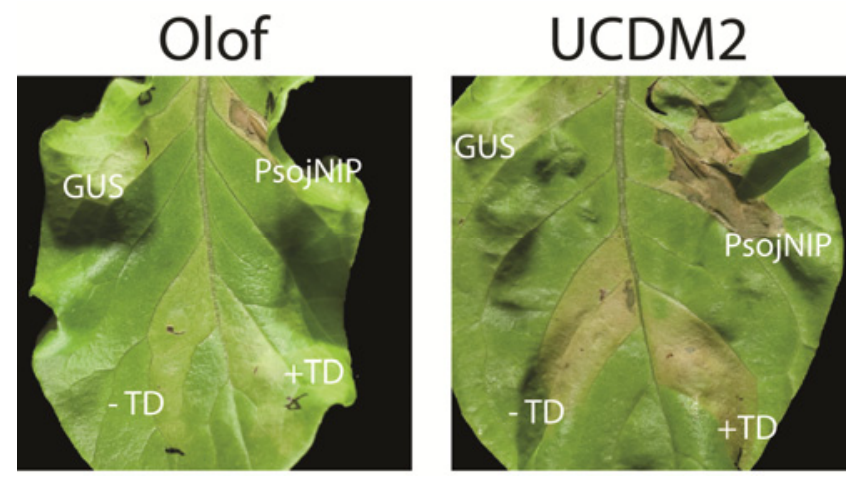

Fig. 5. Recognition of BLG03 with (+TD; BLG03 ${ }^{20-243}$ ) and without (-TD; BLG03 ${ }^{58-243}$ ) translocation domain in Lactuca sativa 'UCDM' but not in L. sativa 'Olof'. $\beta$-Glucuronidase (GUS) and PsojNIP serve as controls for responses to Agrobacterium and successful T-DNA transfer, respectively. Pictures were taken 6 days postinoculation.
BLG01 ${ }^{\mathrm{E}}$, this protein will not be produced by the B. lactucae isolates F703 and NL519.

\section{BLG01 recognition in L. saligna CGN05271 is not linked to Bremia resistance.}

To genetically map the locus responsible for the response to BLG01, backcross inbred lines (BIL), which cover $96 \%$ of the L. saligna CGN05271 genome in an L. sativa 'Olof' background (Jeuken and Lindhout 2004), were tested by transient Agrobacterium-mediated expression of the BLG01 alleles A and E. None of the BIL showed a cell death response to BLG01 (Table 3). Because $4 \%$ of the L. saligna genome was absent in the set of $28 \mathrm{BIL}$, the locus could be located in one of the four chromosomal regions (bottom chromosome 3, top chromosome 5 , top chromosome 7 , or bottom chromosome 9) that are not represented in the BIL (Jeuken and Lindhout 2004; Jeuken et al. 2008). From the original L. saligna CGN05271 $\times$ L. sativa 'Olof' F2 mapping population (Jeuken et al. 2001), viable F3, $\mathrm{F} 4$, and BC1S1 families were obtained from selfed parental

Table 2. Distribution of alleles of BLG01, BLG02, and BLG03 over eight Bremia isolates ${ }^{\mathrm{w}}$

\begin{tabular}{llll}
\hline Race & \multicolumn{1}{c}{ BLG01 } & BLG02 & BLG03 \\
\hline $\mathrm{B} 1: 5$ & $\mathrm{C}, \mathrm{D},{ }^{\mathrm{x}} \mathrm{F}^{\mathrm{x}}{ }^{\mathrm{G}} \mathrm{G}^{\mathrm{y}}$ & $\mathrm{A}, \mathrm{E}$ & $\mathrm{B}, \mathrm{G}$ \\
$\mathrm{B} 1: 16$ & $\mathrm{~A}, \mathrm{~B}$ & $\mathrm{~A}, \mathrm{~B}^{\mathrm{z}}$ & $\mathrm{A}$ \\
$\mathrm{B} 1: 17$ & na & $\mathrm{A}, \mathrm{C}$ & $\mathrm{D}, \mathrm{F}^{\mathrm{y}}$ \\
$\mathrm{B} 1: 24$ & $\mathrm{~A}$ & $\mathrm{~A}, \mathrm{~B}^{\mathrm{z}}$ & $\mathrm{A}, \mathrm{C}$ \\
$\mathrm{NL} 519$ & $\mathrm{E}^{\mathrm{x}}$ & $\mathrm{B},{ }^{\mathrm{z}} \mathrm{C}$ & $\mathrm{A}, \mathrm{D}$ \\
F703 & $\mathrm{E}^{\mathrm{x}}$ & $\mathrm{C}, \mathrm{D}$ & na \\
CA3 & $\mathrm{C}$ & $\mathrm{A}, \mathrm{F}$ & $\mathrm{A}$ \\
CA6 & $\mathrm{C}$ & $\mathrm{A}$ & $\mathrm{A}, \mathrm{E}$ \\
\hline
\end{tabular}

${ }^{\mathrm{w}}$ Abbreviation: na $=$ not amplified.

${ }^{\mathrm{x}}$ Premature stop codon before translocation domain.

y Premature stop codon after translocation domain.

${ }^{\mathrm{z}}$ Encodes same protein sequence as A.

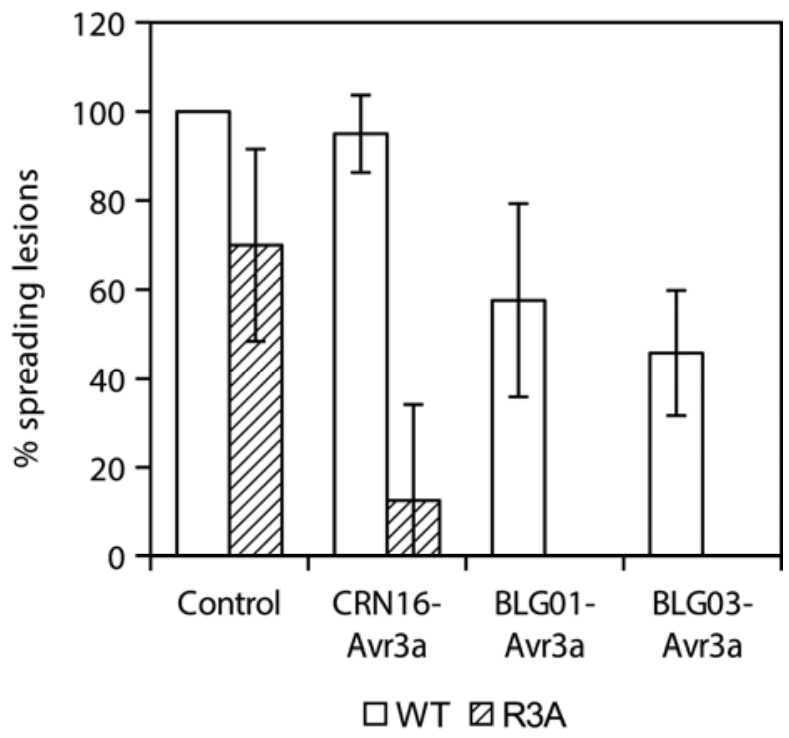

Fig. 6. N termini of BLG01 and BLG03 allow translocation of AVR3a from Phytophthora capsici into Nicotiana benthamiana cells. Mycelial plugs of $P$. capsici LT3112 (control) and transformants thereof carrying the AVR3a fusion constructs were inoculated onto $N$. benthamiana wild-type (WT) and R3A leaves. Inoculation sites were scored for lesion formation 7 days after inoculation and the percentage of spreading lesions was determined. Data represent three independent experiments. The reduction in the percentage of spreading lesions on R3a plants relative to that on WT plants was similar for CRN16-AVR3a, BLG01-AVR3a, and BLG03-AVR3a, whereas the reduction in the percentage of spreading lesions was significantly lower in the control $(P<0.05)$. 
lines that were heterozygous or homozygous L. saligna at one of the four regions that were not represented in the BIL. Several families were found to segregate for cell death in response to both allele $\mathrm{BLG}_{01}^{\mathrm{A}}$ and allele $\mathrm{BLG}^{\mathrm{E}}{ }^{\mathrm{E}}$ (Table 3). Most F3 plants that were responsive to the stronger $\mathrm{BLG} 01^{\mathrm{E}}$ allele were also responsive to the $\mathrm{BLG} 01^{\mathrm{A}}$ allele. Only six plants responsive to $\mathrm{BLG} 01^{\mathrm{E}}$ were not visually scored as responsive to $\mathrm{BLG} 01^{\mathrm{A}}$, probably because of the weaker response to BLG01 ${ }^{\mathrm{A}}$. This segregation was also observed in F3 plants from a cross between the responsive L. saligna parent CGN11341 and the nonresponsive L. sativa parent 'Norden' (Table 3). Comparing the parental genotypes from the families that showed cell death revealed that the response to BLG01 was linked to a region at the bottom of chromosome 9 that was always homozygous or heterozygous $L$. saligna, indicating that the trait is dominant. This was confirmed in four F1 plants obtained from a cross between CGN05271 and 'Olof' that were all responsive to the effector (Table 3). The position of the locus on chromosome 9 was further confirmed and more precisely positioned using F3 families, of which the F2 parent had a recombination event near the candidate region. Thus, the locus could be mapped to a region of 4.4 centimorgans (cM) between markers CLSX3110 and CLS_S3_4656, as shown by the genotype of four informative F3 plants (Fig. 7).

The BLG01-triggered response resembles ETI and, therefore, was expected to be causally linked to B. lactucae resistance. The responsive $L$. saligna line CGN05271 is a nonhost for $B$. lactucae, because of multiple quantitative resistance loci (Zhang et al. 2009a and b); therefore, we tested segregating families for linkage of the response to BLG01 and the B. lactucae resistance phenotype. Both BC1S2 families obtained from BC1S1 plants 90_2 and 90_6 that were responsive to BLG01 were as susceptible to isolate $\mathrm{Bl}: 24$ as the L. sativa 'Olof' parent (Table 4). We conclude that the locus for responsiveness to BLG01 does not confer resistance to B. lactucae isolate $\mathrm{Bl}: 24$ that expresses the recognized effector protein.

\section{BLG03 recognition and Bremia resistance are linked to the $D m 2$ gene.}

BLG03 is recognized by lettuce lines Amplus and UCDM2 (Fig. 1), which carry known resistance loci to B. lactucae. Amplus contains two $R$ genes, $D m 2$ and $D m 4$, whereas UCDM2 contains a single locus, $D m 2$. Therefore, these two lines have the Dm2 locus in common, which is absent from the other tested lines. This raised the possibility that the $D m 2$-encoded $\mathrm{R}$ protein mediates BLG03 recognition. We investigated whether resistance to $B$. lactucae isolate $\mathrm{Bl}: 5$, to which lettuce $D m 2$ confers resistance, co-segregated with the ability to recognize BLG03 in an F2 population of a UCDM $2 \times$ Cobham Green cross, in which the Dm2 resistance locus segregates. The response to BLG03 was determined by Agrobacterium infiltration in leaves, and resistance to B. lactucae $\mathrm{Bl}: 5$ was determined in a leaf disc assay. Of 143 tested F2 plants, all but 28 developed a clear cell death in response to transient expression
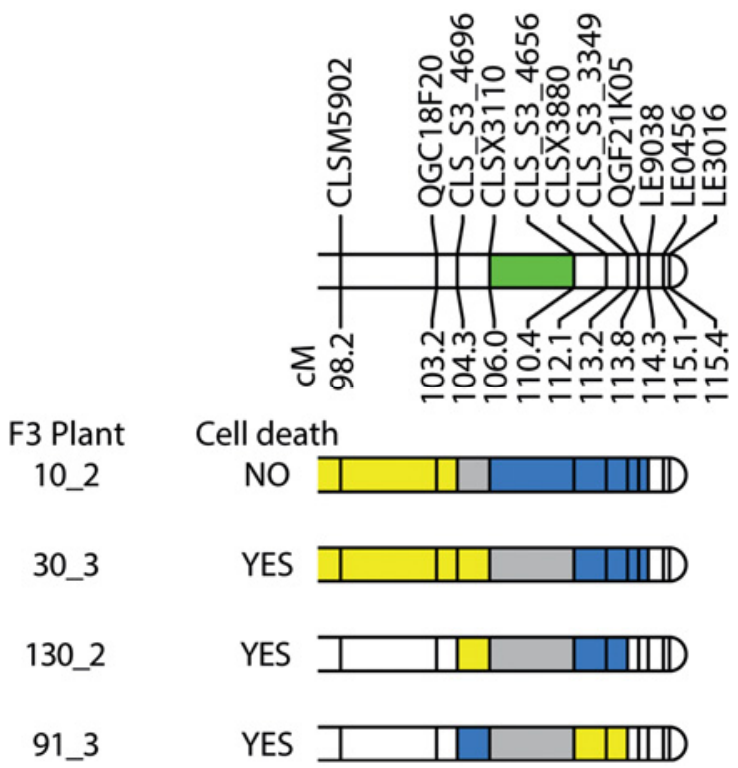

Fig. 7. Locus of the BLG01 cell-death response in Lactuca saligna CGN05271 at the bottom of chromosome 9. Genotype graphs for four F3 plants with the closest recombination are shown. Blue is homozygous $L$. sativa 'Olof', yellow is heterozygous, gray represents intervals with a recombination event, and white means unknown genotype. Green indicates the smallest region in which the cell-death response to BLG01 is fine mapped.

Table 3. Response to BLG01 transient expression in Lactuca saligna and L. sativa parental lines and progeny ${ }^{\mathrm{z}}$

\begin{tabular}{|c|c|c|c|c|c|c|}
\hline \multirow[b]{3}{*}{ Lines, populations } & \multicolumn{3}{|c|}{ Assay 1 and 2} & \multicolumn{2}{|c|}{ Assay 3} & \multirow[b]{3}{*}{ Remark } \\
\hline & \multirow[b]{2}{*}{ Plants tested } & \multicolumn{2}{|c|}{ Responsive plants } & \multirow[b]{2}{*}{ Plants tested } & \multirow{2}{*}{$\frac{\text { Responsive plants }}{\text { BLG01 }^{\mathrm{E}}}$} & \\
\hline & & BLG01 $^{\mathrm{E}}$ & BLG01 $^{A}$ & & & \\
\hline L. sativa 'Olof' & 6 & 0 & 0 & 3 & 0 & Nonresponsive parent \\
\hline L. saligna CGN05271 & 6 & 6 & 6 & 3 & 3 & Responsive parent \\
\hline Set of 28 BIL & 84 & 0 & 0 & $\ldots$ & $\ldots$ & $\ldots$ \\
\hline $\mathrm{BC} 1 \mathrm{~S} 1$ & 5 & $2(1)$ & $1(1)$ & $\ldots$ & $\ldots$ & $\ldots$ \\
\hline F3 & 48 & $15(11)$ & $13(9)$ & 74 & $19(8)$ & $\ldots$ \\
\hline F4 & 3 & $3(1)$ & $2(1)$ & $\ldots$ & $\ldots$ & $\ldots$ \\
\hline $\mathrm{F} 1$ & $\ldots$ & $\ldots$ & $\ldots$ & 4 & 4 & $\ldots$ \\
\hline L. sativa 'Norden' & 4 & 0 & 0 & 2 & 0 & Nonresponsive parent \\
\hline L. saligna CGN11341 & 7 & 7 & 7 & 3 & 3 & Responsive parent \\
\hline F3 & 14 & $7(4)$ & $5(4)$ & 3 & $3(2)$ & $\ldots$ \\
\hline
\end{tabular}

${ }^{\mathrm{y}}$ Numbers in parentheses indicate the number of families. BIL $=$ backcross inbred lines.

Table 4. Disease assessment by detached leaf assay at adult plant stage, $\mathrm{ADT}_{\mathrm{G}}$, with Bremia lactucae $\mathrm{Bl}: 24$ on genotyped $\mathrm{BC} 1 \mathrm{~S} 2$ populations from two BC1S1 plants that showed a cell-death response to BLG03 ${ }^{\mathrm{E}}$

\begin{tabular}{llccc}
\hline Plant & Genotype bottom C9 & Number of plants tested & Number of leaf segments & Race B1:24 ISL \\
\hline BC1S2 90_2 & Homozygous Lactuca sativa & 3 & 18 & 84 \\
& Heterozygous & 6 & 36 & 75 \\
BC1S2 90_6 & Homozygous L. sativa & 3 & 18 & 75 \\
& Heterozygous & 6 & 36 & 92 \\
L. sativa 'Olof' & Homozygous L. sativa & 3 & 27 & 84 \\
\hline
\end{tabular}


of BLG03 (four sites per plant), indicating that the ability to recognize the effector is a dominant trait. All plants that recognized BLG03 were resistant to B1:5. Conversely, all plants that did not recognize BLG03 were susceptible to B1:5. This indicates that $D m 2$ or a closely linked gene from the $D m 2$ background is required for recognition of BLG03.

To investigate the link between BLG03 recognition and Dm2 further, we tested all available BLG03 alleles on 'Olof' (negative control), UCDM2, and Amplus. Alleles A to E were able to induce cell death responses in UCDM2 and Amplus. Alleles $\mathrm{F}$ and $\mathrm{G}$ did not induce a cell death response in any of the tested lines.

Because Amplus and UCDM2 are susceptible to B. lactucae isolate Bl:24, from which we initially cloned BLG03, we set out to investigate whether any of the other effectors cloned from $\mathrm{Bl}: 24$ could suppress the cell death response induced by BLG03. We inoculated a mixture (total optical density at 600 $\mathrm{nm}=0.8$ ) of BLG03 and individual other effector genes at ratios of 1:2 (UCDM2) or 1:3 (Amplus). These ratios were determined as the lowest Agrobacterium-BLG03/AgrobacteriumGUS ratio at which a consistent cell death response could be seen. Using this setup, we did not find any reduction of the cell death responses induced by BLG03 in combination with any of the 33 other effectors compared with the combination of BLG03 and GUS. A similar setup using BLG01 in L. saligna CGN05271 also did not reveal any reduction of BLG01induced cell death responses by other effectors.

\section{DISCUSSION}

\section{In planta effector recognition.}

Two B. lactucae RXLR-like effectors were identified that are specifically recognized in Lactuca breeding material. A relatively large number of wild lettuce accessions are capable of recognizing BLG01 and mounting a cell death response. BLG03, in contrast, is recognized specifically in two cultivated lettuce lines that share the $D m 2$ resistance specificity. Our $B$. lactucae effector screen of effectors for in planta recognition has uncovered potential gene-for-gene interactions. The screening of 54 effectors of the oomycete $P$. infestans in 10 wild Solanum genotypes by transformation with Potato virus $X$ (PVX) uncovered 36 specific interactions (Vleeshouwers et al. 2008). In contrast, screening of 60 effectors of the downy mildew $H$. arabidopsidis in 12 Arabidopsis thaliana accessions using Pseudomonas syringae pv. DC3000 for delivery did not uncover any HR (cell death) upon effector delivery (Fabro et al. 2011).

Wild Lactuca spp. can be used to introgress $R$ genes or QTLs into lettuce cultivars. For example, the Dm3 gene originates from a $L$. serriola accession but is very rare in natural populations, with only a single accession of 1,033 tested from 49 natural populations having an intact $D m 3$ gene (Kuang et al. 2006). $D m 3$ is a fast-evolving $R$ gene from the RGC2 locus. This locus encodes two types of $R$ gene candidates, a fastevolving type and a type that evolves at a much slower rate and is more conserved among different accessions (Kuang et al. 2004). Recognition of the B. lactucae effector BLG01 appears to be relatively common in L. saligna species and to only occur sporadically in other species. The wide recognition of BLG01 may indicate recognition by a slowly evolving or more ancient $R$ gene. The exact nature of the recognition of BLG01 in $L$. saligna and whether this recognition is dependent on the same gene in all lines remains to be determined.

The recognition of BLG01 in L. saligna CGN05271 was mapped at the bottom of chromosome 9, where no $R$ gene clusters to B. lactucae in $L$. serriola and L. sativa are known thus far (Kesseli et al. 1994; Truco et al. 2007). None of the 23 lettuce expressed sequence tag (EST) sequences from the Lettuce SFP Chip Project that are mapped within the 4.4-cM region between our flanking markers (CLSX3110 and CLS_S3_4656) show homology to NB-LRR-like resistance proteins. We are aware of only three $R$ genes from $L$. saligna that have been introgressed into L. sativa, none of which are located on chromosome 9 (Moreau 1994; Segura et al. 2011; Van Ettekoven and Van der Arend 1999). Interestingly, the cell death response to the $P$. syringae effector AvrPto did map in the same region on chromosome 9 in a $L$. sativa $\times$ L. serriola recombinant inbred line (RIL) population (McHale et al. 2009).

BLG03 is recognized in only two lettuce breeding lines of the initial screen. These lines share the Dm2 resistance locus, which maps in or near the RGC2 locus (Meyers et al. 1998). The Dm2 locus provides resistance to $\mathrm{Bl}: 5$, and recognition of BLG03 correlated with resistance to Bl:5 in $143 \mathrm{~F} 2$ plants of a UCDM $2 \times$ Cobham Green cross, in which Dm2 segregates. This indicates that the response to BLG03 maps to the RGC2 locus in UCDM2. Sequencing of BLG03 in eight different isolates revealed seven different alleles. Of the sequenced $B$. lactucae isolates, B1:5 and F703 are unable to successfully infect Dm2-containing hosts. We were not able to amplify BLG03 from $B$. lactucae isolate F703, although the quality of DNA was not a problem because we could amplify BLG01 and BLG02. Both Bl:5 BLG03 alleles (B and G) were not found in other sequenced $B$. lactucae isolates. One of the Bl:5 alleles $\left(\mathrm{BLG} 03^{\mathrm{G}}\right)$ did not induce a visible response in Dm2-containing lines but the other $\left(\mathrm{BLG}_{03}{ }^{\mathrm{B}}\right)$ was recognized in the same lines as the $\mathrm{Bl}: 24$ reference allele $\left(\mathrm{BLG} 03^{\mathrm{A}}\right)$. The fact that resistance to isolate $\mathrm{Bl}: 5$ and recognition $\mathrm{BLG} 03^{\mathrm{B}}$ are fully linked in a segregating F2 population strongly suggests that the effector could be the avirulence protein Avr2 that is recognized by the Dm2 gene.

\section{Effector recognition versus resistance.}

In most reported cases, effector recognition is linked to resistance. Recognition of BLG01, however, was not linked to resistance to $\mathrm{Bl}: 24$ in laboratory assays, and BLG03 was cloned from a B. lactucae isolate that can successfully infect the lettuce lines in which BLG03 is recognized. Examples of a lack of correlation between recognition of an effector and resistance to pathogen isolates that express the effector have previously been reported. Screening of 54 Phytophthora infestans effectors in Solanum spp. by PVX expression uncovered two interactions that were not correlated to resistance. In an F2 population of a cross between a resistant and susceptible Solanum sp., no correlation between the ability to recognize certain $P$. infestans effectors and resistance to $P$. infestans was found, despite perfect correlation between recognition of other $P$. infestans effectors and resistance (Vleeshouwers et al. 2008). Likewise, not all Arabidopsis thaliana accessions that recognize ATR39-1 or ATR1Emco5 are resistant to isolates that encode these alleles (Goritschnig et al. 2012; Krasileva et al. 2011; Rehmany et al. 2005).

An explanation for the lack of resistance in plants that can recognize individual $B$. lactucae effectors is that $B$. lactucae uses additional effectors to suppress ETI. A study that investigated crosses of virulent and avirulent $B$. lactucae isolates revealed a possible locus that inhibits avirulence triggered by Avr5/8 but no evidence for other inhibitors of avirulence in $B$. lactucae (Ilott et al. 1989). The study highlights that inhibitor loci exist but that they are polymorphic. Since this study was performed, over 20 years of selective pressure on B. lactucae has given rise to new isolates that break various resistances. However, none of our 34 tested effectors were able to suppress BLG01- or BLG03-induced cell death. We cannot rule out the existence of suppressors of cell death because our selection of 
effectors is nonexhaustive and suppressors may even be nonRXLR effectors, which we did not investigate.

Findings described for the P. infestans effector AvrSmira2 (Rietman et al. 2012) provide an alternative explanation for an apparent lack of correlation between effector recognition and resistance. Agrobacterium-mediated transient transformation of potato 'Sarpo Mira' with AvrSmira2 induced a cell death response and indicates the presence of a resistance factor named Rpi-Smira2. Cell death responses to AvrSmira2 were found to segregate in offspring of a cross between an Rpi-Smira2-containing parent and a universally susceptible parent. As with our $B$. lactucae effector BLG03, no resistance to $P$. infestans strains containing AvrSmira2 could be scored in plants that showed a cell death response toward AvrSmira2 in laboratory assays. Field trials, however, revealed a partial resistance phenotype correlated with the ability to recognize AvrSmira2. Therefore, field trials in plants containing the L. saligna locus for recognition of BLG01 are important to determine whether the locus confers a partial resistance phenotype and if the locus is of value for breeding B. lactucae-resistant lettuce. Overall, our large effector screen in lettuce has demonstrated, in our opinion, that effector-based approaches are applicable to agriculturally important plant-pathogen systems, yielding both fundamental knowledge on recognition and leads for resistance breeding.

\section{MATERIALS AND METHODS}

\section{Cloning and sequencing.}

Effector predictions were sequence verified from PCR product using flanking primers and sequenced by Macrogen Inc. (Seoul, Korea). All primers used in this study are listed in Supplementary Table 4 . Verified effector candidates were TOPO cloned into the pENTR vector using the pENTR/D-TOPO Cloning kit (Invitrogen, Carlsbad, CA, U.S.A.) according to the manufacturer's instructions starting from the sequence after the predicted signal peptide cleavage site of the effectors, unless otherwise indicated, and were preceded by a newly introduced start codon. Constructs were then recombined into the pK2GW7 vector (Plant-Systems Biology VIB, Ghent, Belgium). Clones were electrotransformed into Agrobacterium tumefaciens C58C1 (pGV2260). The PsojNIP and YFP constructs are described by Cabral and associates (2012). For sequencing of effector alleles, DNA was PCR amplified using primers flanking the coding sequence, blunt-end ligated into pJET1.2 (Fermentas, Vilnius, Lithuania), and transformed into Escherichia coli $\mathrm{DH} 5 \alpha$ by heat-shock. Plasmid isolation and sequencing was carried out by Macrogen Inc.

\section{Lettuce lines for the effector recognition screen.}

Lettuce lines were chosen on the basis of the differential sets EU-A and EU-B proposed by the International B. lactucae Evaluation Board, a set of resistant accessions proposed by Michelmore and Ochoa (1994), parents of RIL-populations segregating for B. lactucae-resistance (Grube and Ochoa 2005; Hand et al. 2003; Jeuken et al. 2001; Truco et al. 2007), and other known sources of B. lactucae-resistance (Hagnefelt and Olsson 1999; Lambalk et al. 2000; Van Treuren et al. 2011). Also, one resistant $L$. aculeata and two resistant $L$. altaica accessions (Van Treuren et al. 2011) were included to widen genetic diversity.

\section{Agrobacterium-mediated transient transformation assay.}

A. tumefaciens strains containing the $35 \mathrm{~S}$-effector T-DNA were grown overnight in selective media at $28^{\circ} \mathrm{C}$ and $220 \mathrm{rpm}$. Cells were spun down at 2,500 $\times g$ for 10 min and resuspended in induction medium $(1 \times \mathrm{M} 9$ salts, $1 \%$ glucose, and $50 \mu \mathrm{M}$ acetosyringone) with appropriate antibiotics. After growth for $4 \mathrm{~h}$ at $28^{\circ} \mathrm{C}$ and $220 \mathrm{rpm}$, cells were spun down at $25,00 \times g$ for $10 \mathrm{~min}$ and resuspended in infiltration medium $(0.5 \times$ Murashige and Skoog salts, $10 \mathrm{mM}$ morpholinoethanesulfonic acid, $0.5 \%$ fructose, $0.5 \%$ sucrose, and $150 \mu \mathrm{M}$ acetosyringone). Strains were then pressure infiltrated into leaves using a needleless syringe. Responses in lettuce lines were scored 8 dpi, unless otherwise indicated. To test whether any of the 34 effectors are recognized in planta, we pressure infiltrated suspensions of the Agrobacterium strains carrying the effector constructs into leaves of the selected lettuce lines. Visual responses to transient expression of effector candidates were scored 5 to 8 days after Agrobacterium infiltration. We included strains carrying a $Y F P$ - or $G U S$-containing vector as a negative control, and a necrosis-inducing protein (NIP) gene-containing vector as a positive control. Expression of $Y F P$ is not expected to elicit visible cell death; therefore, any response seen after infiltration with Agrobacterium carrying the $Y F P$ construct is considered background. The NIP gene encoding PsojNIP that is derived from $P$. sojae induces a cell death response in lettuce that is visible 1 to 2 days after infiltration of the Agrobacterium strain and develops into a dark necrotic lesion after $48 \mathrm{~h}$.

\section{Time course qPCR.}

For time-course experiments, 1-week-old L. sativa 'Olof' seedlings were spray inoculated with 150 spores $\mu \mathrm{l}^{-1}$ until runoff was imminent. Seedlings were grown under high humidity (closed tray with transparent lid) at $17^{\circ} \mathrm{C}$ with $9 \mathrm{~h}$ of light $(100$ $\mu \mathrm{E} / \mathrm{m}^{2} / \mathrm{s}$ ) and kept under these conditions for the duration of the experiment. Samples were taken and snap-frozen immediately after spraying and every $24 \mathrm{~h}$ until $5 \mathrm{dpi}$. Total RNA was extracted using the Spectrum plant total RNA kit (Sigma Life Science, St. Louis) and treated with DNAse (Fermentas). cDNA was synthesized using RevertAid H minus Reverse Transcriptase (Fermentas) and Oligo(dT)15. Cycle thresholds $\left(\mathrm{C}_{\mathrm{T}}\right)$ were determined in triplicate per transcript using the ABI PRISM 7900 HT or the Life Technologies ViiA7 system using SYBR Green as reporter dye. Expression levels were determined as the number of qPCR cycles required for the abundance of each amplicon to reach $C_{\mathrm{T}}$ level, and were normalized to $L$. sativa actin or B. lactucae actin (resulting in $\Delta \mathrm{C}_{\mathrm{T}}$ values).

\section{Effector translocation assay.}

The method for testing the delivery of the effector domain of Avr3a (originally from $P$. infestans) from transgenic $P$. capsici into cells of $N$. benthamiana was performed essentially as described by Schornack and associates (2010). The coding sequences of BLG01 and BLG03, encoding the N-terminal region of the proteins containing the signal peptide and GKLR-DER domain, were amplified from cDNA and cloned into the pTOR::CRN16-AVR3a vector (Schornack et al. 2010) digested with $C l a I / A s c$ I to replace the CRN16 sequence with the BLG sequences. Transformation of $P$. capsici strain LT3112 was performed as described by Huitema and associates (2011). $P$. capsici transformants were inoculated on detached $N$. benthamiana leaves in the form of agar plugs from the border of radially grown colonies on V8 agar plates, and scored 4 to 7 dpi. The reduction in the percentage of spreading lesions on R3a plants relative to that on wild-type plants was calculated as 1 (\% spreading lesions R3a/\% spreading lesions wild type) $\times 100$, and was compared using analysis of variance (ANOVA) and $t$ tests.

\section{Codon-based test for positive selection.}

Insertions and deletions were removed from sequences and sequences with internal stop codons were removed. $\mathrm{dS}$ and $\mathrm{dN}$ substitution rates were calculated using Nei and Gojobori's 
method (Nei and Gojobori 1986), using MEGA4 (Tamura et al. 2007). Standard error was determined by 500 bootstrap replications. The null hypothesis of no selection $(\mathrm{dN}=\mathrm{dS})$ versus the positive selection hypothesis $(\mathrm{dN}>\mathrm{dS})$ was determined using the $\mathrm{Z}$ test: $\mathrm{Z}=(\mathrm{dN}-\mathrm{dS}) / \sqrt{ }[\operatorname{Var}(\mathrm{dS})+\operatorname{Var}(\mathrm{dN})]$.

\section{Materials for mapping the BLG01 response.}

Two crosses of $L$. saligna and $L$. sativa were previously made: cross 1 of $L$. saligna CGN05271 $\times$ L. sativa 'Olof' and cross 2 of L. saligna CGN11341 $\times$ L. sativa Norden (Jeuken et al. 2001). Materials for assays 1,2 , and 3 were as follows. Assay 1 : three replicates of 28 BIL derived from cross 1 that, together, cover $96 \%$ of the L. saligna CGN5271 genome (Jeuken and Lindhout 2004) and the parental lines of cross 1 and cross 2 . Assay 2: F3, F4, and BC1S1 plants derived from cross 1 and cross 2. Assay 3: parental lines of cross 1 and cross 2, F1 offspring of cross 1, and F3 offspring of F2 plants of both cross 1 and cross 2 , with a recombination near the $\mathrm{C} 9$ locus.

\section{Marker development and genotyping.}

For fine mapping, new markers were developed and selected to saturate the region. Based on alignment of our F2 map (improved version of Jeuken and associates [2001], with the $L$. sativa $\times$ L. serriola RIL map by the Lettuce SFP Chip Project and the Compositae Genome Project Database), we selected candidate EST sequences and markers. Primers were developed, tested, and, in the case of polymorphism, run on the segregating populations for mapping. Polymorphisms between $L$. sativa and L. saligna PCR products of the EST markers were visualized by high-resolution melting curve differences on a LightScanner System (Idaho Technology, Salt Lake City, UT, U.S.A.). All plants with a cell death response in transient assay 2 and all the plants from assay 3 were genotyped using the new markers.

\section{Disease test on adult plants.}

A detached-leaf assay was conducted on adult plants (37 days after sowing) according the protocol of $\mathrm{ADT}_{\mathrm{G}}$, as previously described (Jeuken et al. 2008). Two genotyped BC1S2 populations from a BC1S1 plant that showed a cell death response toward BLG01 were tested with B. lactucae Bl:24. From each plant, at least six leaf squares were collected $(2.5$ by $2.5 \mathrm{~cm})$. Leaf squares were inoculated with inoculum from $B$. lactucae isolate $\mathrm{Bl}: 24$ containing $4 \times 10^{5}$ spores per milliliter. At $9 \mathrm{dpi}$, the percentage of the area of each leaf square that showed $B$. lactucae sporulation was determined. One-way ANOVA was used to analyze the data, with line (offspring from one parent with genotype at C9 locus) as fixed factor and each different plant as block factor. For comparison between the heterozygous and homozygous L. sativa genotypes from each $\mathrm{BC} 1 \mathrm{~S} 1$ parent with each other, a Duncan's multiple range test $(\alpha=0.05)$ was performed with GenStat (14th edition) software.

\section{ACKNOWLEDGMENTS}

This project was supported by the foundation TTI Green Genetics (TTI GG, The Netherlands) and was a collaboration among Utrecht University, Wageningen University, and five vegetable breeding companies: Enza zaden (Enkhuizen, The Netherlands), Nunhems (Nunhem, The Netherlands), RijkZwaan (De Lier, The Netherlands), Syngenta (Enkhuizen, The Netherlands), and Vilmorin (La Ménitré, France). We thank H. van Pelt for photography, E. Huitema (University of Dundee, Scotland) for providing materials and protocols for P. capsici transformation, and V. Vleeshouwers (University of Wageningen, The Netherlands) for providing $N$. benthamiana R3 seed.

\section{LITERATURE CITED}

Armstrong, M. R., Whisson, S. C., Pritchard, L., Bos, J. I. B., Venter, E., Avrova, A. O., Rehmany, A. P., Boehme, U., Brooks, K., Cherevach, I.,
Hamlin, N., White, B., Fraser, A., Lord, A., Quail, M. A., Churcher, C. Hall, N., Berriman, M., Huang, S., Kamoun, S., Beynon, J. L., and Birch, P. R. J. 2005. An ancestral oomycete locus contains late blight avirulence gene $A v r 3 a$, encoding a protein that is recognized in the host cytoplasm. Proc. Natl. Acad. Sci. U.S.A. 102:7766-7771.

Avrova, A. O., Boevink, P.C., Young, V., Grenville-Briggs, L.J., van West, P., Birch, P. R. J., and Whisson, S. C. 2008. A novel Phytophthora infestans haustorium-specific membrane protein is required for infection of potato. Cell Microbiol. 10:2271-2284.

Bailey, K., Cevik, V., Holton, N., Byrne-Richardson, J., Sohn, K., Coates, M., Woods-Tor, A., Aksoy, H. M., Hughes, L., Baxter, L., Jones, J. D. G., Beynon, J., Holub, E. B., and Tor, M. 2011. Molecular cloning of ATR5(Emoy2) from Hyaloperonospora arabidopsidis, an avirulence determinant that triggers RPP5-mediated defense in Arabidopsis. Mol. Plant-Microbe Interact. 24:827-838.

Baxter, L., Tripathy, S., Ishaque, N., Boot, N., Cabral, A., Kemen, E., Thines, M., Ah-Fong, A. M. V., Anderson, R., Badejoko, W., BittnerEddy, P., Boore, J. L., Chibucos, M. C., Coates, M. E., Dehal, P., Delehaunty, K., Dong, S., Downton, P., Dumas, B., Fabro, G., Fronick, C., Fuerstenberg, S. I., Fulton, L., Gaulin, E., Govers, F., Hughes, L., Humphray, S., Jiang, R. H. Y., Judelson, H. S., Kamoun, S., Kyung, K., Meijer, H. J. G., Minx, P., Morris, P. F., Nelson, J., Phuntumart, V., Qutob, D., Rehmany, A. P., Rougon-Cardoso, A., Ryden, P., TortoAlalibo, T., Studholme, D. J., Wang, Y., Win, J., Wood, J., Clifton, S. W., Rogers, J., Van den Ackerveken, G., Jones, J. D. G., McDowell, J. M., Beynon, J. L., and Tyler, B. M. 2010. Signatures of adaptation to obligate biotrophy in the Hyaloperonospora arabidopsidis genome. Science 330:1549-1551.

Boller, T., and He, S. Y. 2009. Innate immunity in plants: An arms race between pattern recognition receptors in plants and effectors in microbial pathogens. Science 324:742-744.

Brown, S., Koike, S. T., Ochoa, O. E., Laemmlen, F., and Michelmore, R. W. 2004. Insensitivity to the fungicide fosetyl-aluminum in California isolates of the lettuce downy mildew pathogen, Bremia lactucae. Plant Dis. 88:502-508.

Buttner, D., and He, S. Y. 2009. Type III protein secretion in plant pathogenic bacteria. Plant Physiol. 150:1656-1664.

Cabral, A., Stassen, J. H. M., Seidl, M. F., Bautor, J., Parker, J. E., and Van den Ackerveken, G. 2011. Identification of Hyaloperonospora arabidopsidis transcript sequences expressed during infection reveals isolatespecific effectors. PLoS One 6:e19328. Published online.

Cabral, A., Oome, S., Sander, N., Kuefner, I., Nuernberger, T., and Van den Ackerveken, G. 2012. Nontoxic Nep1-like proteins of the downy mildew pathogen Hyaloperonospora arabidopsidis: Repression of necrosis-inducing activity by a surface-exposed region. Mol. PlantMicrobe Interact. 25:697-708.

Dangl, J. L., and Jones, J. D. G. 2001. Plant pathogens and integrated defence responses to infection. Nature. 411:826-833.

Fabro, G., Steinbrenner, J., Coates, M. E., Ishaque, N., Baxter, L., Studholme, D. J., Korner, E., Allen, R. L., Piquerez, S. J. M., RougonCardoso, A., Greenshields, D., Lei, R., Badel, J. L., Caillaud, M., Sohn, K., Van den Ackerveken, G., Parker, J. E., Beynon, J. L., and Jones, J. D. G. 2011. Multiple candidate effectors from the oomycete pathogen Hyaloperonospora arabidopsidis suppress host plant immunity. PLoS Pathog. 7:e1002348. Published online.

Finn, R. D., Mistry, J., Tate, J., Coggill, P., Heger, A., Pollington, J. E., Gavin, O. L., Gunasekaran, P., Ceric, G., Forslund, K., Holm, L., Sonnhammer, E. L. L., Eddy, S. R., and Bateman, A. 2010. The Pfam protein families database. Nucleic Acids Res. 38:D211-222.

Gilroy, E. M., Breen, S., Whisson, S. C., Squires, J., Hein, I., Kaczmarek, M., Turnbull, D., Boevink, P.C., Lokossou, A., Cano, L. M., Morales, J. G., Avrova, A. O., Pritchard, L., Randall, E., Lees, A., Govers, F., van West, P., Kamoun, S., Vleeshouwers, V. G. A. A., Cooke, D. E. L., and Birch, P. R. J. 2011. Presence/absence, differential expression and sequence polymorphisms between PiAVR2 and PiAVR2-like in Phytophthora infestans determine virulence on $R 2$ plants. New Phytol. 191:763776.

Goritschnig, S., Krasileva, K. V., Dahlbeck, D., and Staskawicz, B. J. 2012. Computational prediction and molecular characterization of an oomycete effector and the cognate Arabidopsis resistance gene. PLoS Genet. 8:e1002502. Published online.

Grube, R. C., and Ochoa, O. E. 2005. Comparative genetic analysis of field resistance to downy mildew in the lettuce cultivars 'Grand Rapids' and 'Iceberg'. Euphytica 142:205-215.

Guo, M., Tian, F., Wamboldt, Y., and Alfano, J. R. 2009. The majority of the type III effector inventory of Pseudomonas syringae pv. tomato DC3000 can suppress plant immunity. Mol. Plant-Microbe Interact. 22:1069-1080

Haas, B. J., Kamoun, S., Zody, M. C., Jiang, R. H. Y., Handsaker, R. E., Cano, L. M., Grabherr, M., Kodira, C. D., Raffaele, S., Torto-Alalibo, 
T., Bozkurt, T. O., Ah-Fong, A. M. V., Alvarado, L., Anderson, V. L., Armstrong, M. R., Avrova, A. O., Baxter, L., Beynon, J. L., Boevink, P. C., Bollmann, S. R., Bos, J. I. B., Bulone, V., Cai, G., Cakir, C., Carrington, J. C., Chawner, M., Conti, L., Costanzo, S., Ewan, R., Fahlgren, N., Fischbach, M. A., Fugelstad, J., Gilroy, E. M., Gnerre, S., Green, P. J., Grenville-Briggs, L. J., Griffith, J., Grunwald, N. J., Horn, K., Horner, N. R., Hu, C., Huitema, E., Jeong, D., Jones, A. M. E., Jones, J. D. G., Jones, R. W., Karlsson, E. K., Kunjeti, S. G., Lamour, K., Liu, Z., Ma, L., Maclean, D., Chibucos, M. C., McDonald, H., McWalters, J., Meijer, H. J. G., Morgan, W., Morris, P. F., Munro, C. A., O’Neill, K., Ospina-Giraldo, M., Pinzón, A., Pritchard, L., Ramsahoye, B., Ren, Q., Restrepo, S., Roy, S., Sadanandom, A., Savidor, A., Schornack, S., Schwartz, D. C., Schumann, U. D., Schwessinger, B., Seyer, L., Sharpe, T., Silvar, C., Song, J., Studholme, D. J., Sykes, S., Thines, M., van de Vondervoort, P. J. I., Phuntumart, V., Wawra, S., Weide, R., Win, J., Young, C., Zhou, S., Fry, W., Meyers, B. C., van West, P., Ristaino, J., Govers, F., Birch, P. R. J., Whisson, S. C., Judelson, H. S., and Nusbaum, C. 2009. Genome sequence and analysis of the Irish potato famine pathogen Phytophthora infestans. Nature 461:393-398.

Hagnefelt, A., and Olsson, K. 1999. Breeding of iceberg lettuce. Sver. Utsadesforen. Tidskr. 109:28-34

Hand, P., Kift, N., McClement, S., Lynn, J. R., Grube, R. C., Schut, J. W., Arend, A. J. M., and Pink, D. A. C. 2003. Progress towards mapping QTLs for pest and disease resistance in lettuce. Pages 31-35 in: Eucarpia Leafy Vegetables 2003. T. J. L. Van Hintum, A. Lebeda, D. Pink, and J. W. Schut, eds. Centre for Genetic Resources, Wageningen, The Netherlands.

Huitema, E., Smoker, M., and Kamoun, S. 2011. A straightforward protocol for electro-transformation of Phytophthora capsici zoospores. Methods Mol. Biol. 712:129-135.

Ilott, T., Hulbert, S., and Michelmore, R. W. 1989. Genetic analysis of the gene-for-gene interaction between lettuce (Lactuca sativa) and Bremia lactucae. Phytopathology 79:888-897.

Jeuken, M. J. W., and Lindhout, P. 2002. Lactuca saligna, a non-host for lettuce downy mildew (Bremia lactucae), harbors a new race-specific Dm gene and three QTLs for resistance. Theor. Appl. Genet. 105:384391.

Jeuken, M. J. W., and Lindhout, P. 2004. The development of lettuce backcross inbred lines (BILs) for exploitation of the Lactuca saligna (wild lettuce) germplasm. Theor. Appl. Genet. 109:394-401.

Jeuken, M. J. W., van Wijk, R., Peleman, J., and Lindhout, P. 2001. An integrated interspecific AFLP map of lettuce (Lactuca) based on two $L$. sativa $\times$ L. saligna $\mathrm{F} 2$ populations. Theor. Appl. Genet. 103:638-647.

Jeuken, M. J. W., Pelgrom, K., Stam, P., and Lindhout, P. 2008. Efficient QTL detection for nonhost resistance in wild lettuce: Backcross inbred lines versus F(2) population. Theor. Appl. Genet. 116:845-857.

Jeuken, M. J., Zhang, N. W., McHale, L. K., Pelgrom, K., den Boer, E., Lindhout, P., Michelmore, R. W., Visser, R. G., and Niks, R. E. 2009. Rin4 causes hybrid necrosis and race-specific resistance in an interspecific lettuce hybrid. Plant Cell 21:3368-3378.

Jiang, R. H. Y., Tripathy, S., Govers, F., and Tyler, B. M. 2008. RXLR effector reservoir in two Phytophthora species is dominated by a single rapidly evolving superfamily with more than 700 members. Proc. Natl. Acad. Sci. U.S.A. 105:4874-4879.

Jones, J. D. G., and Dangl, J. L. 2006. The plant immune system. Nature 444:323-329.

Kemen, E., and Jones, J. D. G. 2012. Obligate biotroph parasitism: Can we link genomes to lifestyles? Trends Plant Sci. 17:448-457.

Kesseli, R. V., Paran, I., and Michelmore, R. W. 1994. Analysis of a detailed genetic linkage map of Lactuca sativa (lettuce) constructed from RFLP and RAPD markers. Genetics 136:1435-1446.

Krasileva, K. V., Zheng, C., Leonelli, L., Goritschnig, S., Dahlbeck, D., and Staskawicz, B. J. 2011. Global analysis of Arabidopsis/downy mildew interactions reveals prevalence of incomplete resistance and rapid evolution of pathogen recognition. PLoS One 6:e28765. Published online.

Kuang, H., Woo, S., Meyers, B. C., Nevo, E., and Michelmore, R. W. 2004. Multiple genetic processes result in heterogeneous rates of evolution within the major cluster disease resistance genes in lettuce. Plant Cell 16:2870-2894.

Kuang, H., Ochoa, O. E., Nevo, E., and Michelmore, R. W. 2006. The disease resistance gene $D m 3$ is infrequent in natural populations of $\mathrm{Lac}$ tuca serriola due to deletions and frequent gene conversions at the $R G C 2$ locus. Plant J. 47:38-48.

Lambalk, J. J. M., Faber, N. M., Bruijnis, A. B., Conijn, P. C. J., den Witte, I. A., Nieuwenhuis, J., and de Jong, C. J. 2000. Method for obtaining a plant with a lasting resistance to a pathogen. Patent PCT/ NL2000/000241.

McDonald, B. A., and Linde, C. 2002. Pathogen population genetics, evo- lutionary potential, and durable resistance. Annu. Rev. Phytopathol. 40:349-379.

McHale, L. K., Truco, M. J., Kozik, A., Wroblewski, T., Ochoa, O. E., Lahre, K. A., Knapp, S. J., and Michelmore, R. W. 2009. The genomic architecture of disease resistance in lettuce. Theor. Appl. Genet. 118:565-580.

Meyers, B. C., Chin, D. B., Shen, K. A., Sivaramakrishnan, S., Lavelle, D. O., Zhang, Z., and Michelmore, R. W. 1998. The major resistance gene cluster in lettuce is highly duplicated and spans several megabases. Plant Cell 10:1817-1832.

Michelmore, R. W., and Ochoa, O. E. 1994. Lettuce breeding. Pages 34-44 in: Annual Report 1993-1994. Iceberg Lettuce Advisory Board, Salinas, CA, U.S.A.

Michelmore, R. W., and Wong, J. 2008. Classical and molecular genetics of Bremia lactucae, cause of lettuce downy mildew. Eur. J. Plant Pathol. 122:19-30.

Moreau, B. M. D. 1994. Fungus resistant plants. European patent application EP94810296.

Na, R., Yu, D., Qutob, D., Zhao, J., and Gijzen, M. 2013. Deletion of the Phytophthora sojae avirulence gene Avrld causes gain of virulence on Rpsld. Mol. Plant-Microbe Interact. 26: 969-976.

Nei, M., and Gojobori, T. 1986. Simple methods for estimating the numbers of synonymous and nonsynonymous nucleotide substitutions. Mol. Biol. Evol. 3:418-426.

O'Connell, R. J., and Panstruga, R. 2006. Tete a tete inside a plant cell: Establishing compatibility between plants and biotrophic fungi and oomycetes. New Phytol. 171:699-718.

Qutob, D., Tedman-Jones, J., Dong, S., Kuflu, K., Pham, H., Wang, Y., Dou, D., Kale, S. D., Arredondo, F. D., Tyler, B. M., and Gijzen, M. 2009. Copy number variation and transcriptional polymorphisms of Phytophthora sojae RXLR effector genes Avrla and Avr3a. PLoS One 4:e5066. Published online

Rehmany, A. P., Gordon, A., Rose, L. E., Allen, R. L., Armstrong, M. R. Whisson, S. C., Kamoun, S., Tyler, B. M., Birch, P. R. J., and Beynon, J. L. 2005. Differential recognition of highly divergent downy mildew avirulence gene alleles by RPP1 resistance genes from two Arabidopsis lines. Plant Cell 17:1839-1850.

Rietman, H., Bijsterbosch, G., Cano, L. M., Lee, H., Vossen, J. H., Jacobsen, E., Visser, R. G. F., Kamoun, S., and Vleeshouwers, V. G. A. A. 2012 Qualitative and quantitative late blight resistance in the potato cultivar Sarpo Mira is determined by the perception of five distinct RXLR effectors. Mol. Plant-Microbe Interact. 25:910-919.

Schornack, S., van Damme, M., Bozkurt, T. O., Cano, L. M., Smoker, M. Thines, M., Gaulin, E., Kamoun, S., and Huitema, E. 2010. Ancient class of translocated oomycete effectors targets the host nucleus. Proc. Natl. Acad. Sci. U.S.A. 107:17421-17426.

Segura, V., Briggs, W., Zonneveld, O., and de Lange, M. 2011. Plant resistant to a pathogen. Patent application PCT/EP2010/059268.

Song, T., Kale, S. D., Arredondo, F. D., Shen, D., Su, L., Liu, L., Wu, Y., Wang, Y., Dou, D., and Tyler, B. M. 2013. Two RxLR avirulence genes in Phytophthora sojae determine soybean Rpslk-mediated disease resistance. Mol. Plant-Microbe Interact. 26:711-720

Spanu, P. D. 2012. The genomics of obligate (and nonobligate) biotrophs. Annu. Rev. Phytopathol. 50:91-109.

Stassen, J. H. M., and Van den Ackerveken, G. 2011. How do oomycete effectors interfere with plant life? Curr. Opin. Plant Biol. 14:407-414.

Stassen, J. H. M., Seidl, M. F., Vergeer, P. W. J., Nijman, I. J., Snel, B., Cuppen, E., and Van den Ackerveken, G. 2012. Effector identification in the lettuce downy mildew Bremia lactucae by massively parallel transcriptome sequencing. Mol. Plant Pathol. 13:719-731.

Takken, F. L., and Goverse, A. 2012. How to build a pathogen detector: Structural basis of NB-LRR function. Curr. Opin. Plant Biol. 15:375384.

Tamura, K., Dudley, J., Nei, M., and Kumar, S. 2007. MEGA4: Molecular evolutionary genetics analysis (MEGA) software version 4.0. Mol. Biol. Evol. 24:1596-1599.

Thomma, B. P. H. J., Nuernberger, T., and Joosten, M. H. A. J. 2011. Of PAMPs and effectors: The blurred PTI-ETI dichotomy. Plant Cell 23:415

Tian, M., Win, J., Savory, E., Burkhardt, A., Held, M., Brandizzi, F., and Day, B. 2011. 454 Genome sequencing of Pseudoperonospora cubensis reveals effector proteins with a QXLR translocation motif. Mol. PlantMicrobe Interact. 24:543-553.

Truco, M. J., Antonise, R., Lavelle, D. O., Ochoa, O., Kozik, A., Witsenboer, H., Fort, S.B., Jeuken, M. J. W., Kesseli, R. V., Lindhout, P., Michelmore, R. W., and Peleman, J. 2007. A high-density, integrated genetic linkage map of lettuce (Lactuca spp.). Theor. Appl. Genet. 115:735-746.

Van Ettekoven, C., and Van der Arend, A. J. M. 1999. Identification and denomination of "new" races of Bremia lactucae. Pages 105-107 in 
Proceedings of Eucarpia Meeting on Leafy Vegetables Genetics and Breeding. Olomuc, Czech Republic.

Van Treuren, R., Van der Arend, A. J. M., and Schut, J. W. 2011. Distribution of downy mildew (Bremia lactucae Regel) resistances in a genebank collection of lettuce and its wild relatives. Plant Genet. Resour. 11:15-25.

Vleeshouwers, V. G. A. A., Rietman, H., Krenek, P., Champouret, N., Young, C., Oh, S., Wang, M., Bouwmeester, K., Vosman, B., Visser, R. G. F., Jacobsen, E., Govers, F., Kamoun, S., and Van der Vossen, E. A. G. 2008. Effector genomics accelerates discovery and functional profiling of potato disease resistance and Phytophthora infestans avirulence genes. PLoS One 3:e2875. Published online.

Wang, Q., Han, C., Ferreira, A. O., Yu, X., Ye, W., Tripathy, S., Kale, S. D., Gu, B., Sheng, Y., Sui, Y., Wang, X., Zhang, Z., Cheng, B., Dong, S., Shan, W., Zheng, X., Dou, D., Tyler, B. M., and Wang, Y. 2011 Transcriptional programming and functional interactions within the Phytophthora sojae RXLR effector repertoire. Plant Cell 23:2064-2086.

Whisson, S. C., Boevink, P. C., Moleleki, L., Avrova, A. O., Morales, J. G., Gilroy, E. M., Armstrong, M. R., Grouffaud, S., van West, P., Chapman, S., Hein, I., Toth, I. K., Pritchard, L., and Birch, P. R. J. 2007. A translocation signal for delivery of oomycete effector proteins into host plant cells. Nature 450:115-118.
Zhang, N. W., Lindhout, P., Niks, R. E., and Jeuken, M. J. W. 2009a. Genetic dissection of Lactuca saligna nonhost resistance to downy mildew at various lettuce developmental stages. Plant Pathol. 58:923-932.

Zhang, N. W., Pelgrom, K., Niks, R. E., Visser, R. G. F., and Jeuken, M. J. W. 2009b. Three combined quantitative trait loci from nonhost Lactuca saligna are sufficient to provide complete resistance of lettuce against Bremia lactucae. Mol. Plant-Microbe Interact. 22:1160-1168.

\section{AUTHOR-RECOMMENDED INTERNET RESOURCES}

The International Bremia Evaluation Board on the website of the International Seed Federation: www.worldseed.org/isf/ibeb.htm

University of California Davis Compositae Genome Project database: compgenomics.ucdavis.edu

University of California Davis Lettuce Genome Resource database: lgr.genomecenter.ucdavis.edu

University of California Davis Lettuce SFP Chip Project website: chiplett.ucdavis.edu

Wageningen University's Center for Genetic Resources, the Netherlands website: www.wageningenur.nl/en/Expertise-Services/Legal-researchtasks/Centre-for-Genetic-Resources-the-Netherlands-1.htm 